Check for updates

Cite this: Chem. Commun., 2021, 57,10194

Received 21st June 2021,

Accepted 2nd September 2021

DOI: $10.1039 / \mathrm{d} 1 \mathrm{cc} 03297 f$

rsc.li/chemcomm

\section{Tungsten disulfide thin films via electrodeposition from a single source precursor $\dagger$}

\author{
Shibin Thomas, (D)*a Victoria K. Greenacre, ${ }^{* a}$ Danielle E. Smith, ${ }^{a}$ Yasir J. Noori, ${ }^{b}$ \\ Nema M. Abdelazim, ${ }^{b}$ Andrew L. Hector, (D) ${ }^{a}$ C. H. (Kees) de Groot, (D) b \\ William Levason, (D) ${ }^{a}$ Philip N. Bartlett ${ }^{a}$ and Gillian Reid (D) *a
}

\begin{abstract}
We report a simple process for the electrodeposition of tungsten disulfide thin films from a $\mathrm{CH}_{2} \mathrm{Cl}_{2}$-based electrolyte using a tailored single source precursor, $\left[\mathrm{NEt}_{4}\right]_{2}\left[\mathrm{WS}_{2} \mathrm{Cl}_{4}\right]$. This new precursor incorporates the 1:2 W:S ratio required for formation of $W_{2}$, and eliminates the need for an additional proton source in the electrolyte to remove excess sulfide. The electrochemical behaviour of $\left[\mathrm{NEt}_{4}\right]_{2}\left[\mathrm{WS}_{2} \mathrm{Cl}_{4}\right]$ is studied by cyclic voltammetry and electrochemical quartz crystal microbalance techniques, and the $\mathrm{WS}_{2}$ thin films are grown by potentiostatic electrodeposition.
\end{abstract}

Transition metal dichalcogenides (TMDCs) are an intriguing class of semiconducting materials due to their unique electronic and optical properties and tuneable band gaps, making them highly attractive candidates for nano- and atomic-scale devices. Structurally, they are layered materials with strong covalent bonds within the layers and weak van der Waals interactions between the layers. This weak interlayer bonding in TMDCs facilitates the fabrication of ultra-thin $2 \mathrm{D}$ single- and few-layer materials, the properties of which are distinctly different from their bulk phase, for example, exhibiting direct rather than indirect band gaps and with high carrier mobilities. ${ }^{2}$

Realisation of the potential of few-layer TMDCs in next generation devices requires scalable methods to deposit and pattern the materials. Techniques including physical and chemical vapour deposition, ${ }^{3,4}$ atomic layer deposition, ${ }^{5}$ and pulsed laser deposition ${ }^{6}$ are options, however, they each have their disadvantages.

Electrodeposition is an alternative deposition technique that is easily scalable, is typically performed at or near room

\footnotetext{
${ }^{a}$ School of Chemistry, University of Southampton, Southampton SO17 1BJ, UK.

E-mail: shibin.thomas@soton.ac.uk,v.k.greenacre@soton.ac.uk, g.reid@soton.ac.uk

${ }^{b}$ School of Electronics and Computer Science, University of Southampton,

Southampton SO17 1BJ, UK

$\dagger$ Electronic supplementary information (ESI) available. CCDC 2084213. For ESI and crystallographic data in CIF or other electronic format see DOI: 10.1039/ d1cc03297f
}

temperature and can be readily localised and controlled, making it very attractive for fabricating complex nanoscale features in low dimensional devices. Electrodeposition has been demonstrated for aqueous deposition of a small number of TMDCs, primarily $\mathrm{MoS}_{2}$, and mainly for electrocatalytic applications where rough, irregular morphologies are favoured. ${ }^{7}$ Even though the hydrogen evolution in aqueous electrolytes is advantageous in some cases, such as in nanostructuring of metal deposits, ${ }^{8}$ it restricts the potential window and limits the range of different TMDCs that are accessible by this method. Consequently, non-aqueous electrolytes are of interest for the controlled growth of these materials and there have been a few reported studies on the non-aqueous electrodeposition of $\mathrm{MoS}_{2} \cdot{ }^{9-12}$ However studies of the electrodeposition of $\mathrm{WS}_{2}$, an equally important $2 \mathrm{D}$ material, are very limited. ${ }^{13-17}$

Possible single source precursors for $\mathrm{MoS}_{2}$ or $\mathrm{WS}_{2}$ electrodeposition are the $\left[\mathrm{MS}_{4}\right]^{2-}$ dianions, but the problem here is in getting rid of the excess S. For the electrodeposition of $\mathrm{MoS}_{2}$ from non-aqueous solution this can be achieved by the addition of a proton source, ${ }^{9}$ but this reduces considerably the faradaic efficiency of the deposition, complicates the process and was not successful for the production of $\mathrm{WS}_{2}$ from $\left[\mathrm{WS}_{4}\right]^{2-}$. Although electrochemical reduction of $\left[\mathrm{NH}_{4}\right]_{2}\left[\mathrm{WS}_{4}\right]$ in $\mathrm{MeCN}$ with added $\mathrm{LiClO}_{4}$ has successfully deposited films, the asdeposited films were S-rich (corresponding to $\mathrm{WS}_{2.8}$ ) and a two stage crystallisation and sulfurisation process was necessary to obtain $\mathrm{WS}_{2} \cdot{ }^{15}$ Our attempts to perform similar electrochemistry in $\mathrm{CH}_{2} \mathrm{Cl}_{2}$ using $\left[\mathrm{N}^{n} \mathrm{Bu}_{4}\right]_{2}\left[\mathrm{WS}_{4}\right]$ were not successful (see ESI $\dagger$ ).

In this paper we describe a new, more efficient and controllable approach using the tungsten(vi) tetrachloridedisulfide dianion, $\left[\mathrm{WS}_{2} \mathrm{Cl}_{4}\right]^{2-}$, specifically designed to overcome this problem, while providing the required 1:2 tungsten:sulfur ratio in order to eliminate the requirements for a proton source.

The single source precursor, $\left[\mathrm{WS}_{2} \mathrm{Cl}_{4}\right]^{2-}$, was synthesised as the $\left[\mathrm{NR}_{4}\right]^{+}\left(\mathrm{R}=\mathrm{Et}\right.$ or $\left.{ }^{n} \mathrm{Bu}\right)$ and $\left[\mathrm{PPh}_{4}\right]^{+}$salts. The anion has been reported previously in $\left[\mathrm{PPh}_{4}\right]_{2}\left[\mathrm{WS}_{2} \mathrm{Cl}_{4}\right]$, made by reaction of $\mathrm{WS}_{2} \mathrm{Cl}_{2}$ and $\left[\mathrm{PPh}_{4}\right] \mathrm{Cl}$ in a $1: 2$ molar ratio in $\mathrm{CH}_{2} \mathrm{Cl}_{2}{ }^{18}$ 
We obtained $\left[\mathrm{PPh}_{4}\right]_{2}\left[\mathrm{WS}_{2} \mathrm{Cl}_{4}\right]$ as a dark brown powder via a new route, by reaction of $\mathrm{WSCl}_{4},{ }^{19} \mathrm{~S}\left(\mathrm{SiMe}_{3}\right)_{2}$ and $\left[\mathrm{PPh}_{4}\right] \mathrm{Cl}$ in $\mathrm{CH}_{2} \mathrm{Cl}_{2}$. $\left[\mathrm{NEt}_{4}\right]_{2}\left[\mathrm{WS}_{2} \mathrm{Cl}_{4}\right]$ was obtained similarly as a brown powder using $\left[\mathrm{NEt}_{4}\right] \mathrm{Cl}$, but the corresponding $\left[\mathrm{N}^{n} \mathrm{Bu}_{4}\right]_{2}\left[\mathrm{WS}_{2} \mathrm{Cl}_{4}\right]$ formed as a sticky solid that was less convenient to handle, hence subsequent studies focussed on the $\left[\mathrm{PPh}_{4}\right]^{+}$and $\left[\mathrm{NEt}_{4}\right]^{+}$salts. The X-ray structure of $\left[\mathrm{PPh}_{4}\right]_{2}\left[\mathrm{WS}_{2} \mathrm{Cl}_{4}\right]$ shows a cis octahedral anion with disordered $\mathrm{S} / \mathrm{Cl}$ groups. ${ }^{18}$ The IR spectrum of the new $\left[\mathrm{NEt}_{4}\right]_{2}\left[\mathrm{WS}_{2} \mathrm{Cl}_{4}\right]$ salt (Fig. S2 ESI $\dagger$ ) contains a strong band at $498 \mathrm{~cm}^{-1}$ assigned as $\nu(\mathrm{W}=\mathrm{S})$, but a cation absorption obscures this region in the spectrum of $\left[\mathrm{PPh}_{4}\right]_{2}\left[\mathrm{WS}_{2} \mathrm{Cl}_{4}\right]$. In $\left[\mathrm{NEt}_{4}\right]_{2}\left[\mathrm{WS}_{2} \mathrm{Cl}_{4}\right]$ the $\nu(\mathrm{W}-\mathrm{Cl})$ region consists of a strong band at $289 \mathrm{~cm}^{-1}$, along with weaker features at 321 and $230 \mathrm{~cm}^{-1}$ (theory $C_{2 \mathrm{v}}=2 A_{1}+B_{1}+B_{2}$ ).

In this work we use dichloromethane as the solvent for the electrochemical experiments because it is relatively inert, much less viscous than ionic liquids, and is only weakly coordinating, simplifying the solution speciation. ${ }^{20}$

The electrochemical behaviour of $\left[\mathrm{NEt}_{4}\right]_{2}\left[\mathrm{WS}_{2} \mathrm{Cl}_{4}\right]$ in $\mathrm{CH}_{2} \mathrm{Cl}_{2}$ was initially studied by performing cyclic voltammetry (CV) experiments. On the initial reduction scan using a TiN electrode, the voltammetry of $\left[\mathrm{NEt}_{4}\right]_{2}\left[\mathrm{WS}_{2} \mathrm{Cl}_{4}\right]$ in dry $\mathrm{CH}_{2} \mathrm{Cl}_{2}$ shows that reduction starts at about $-0.7 \mathrm{~V}$ with a shoulder around $-1.3 \mathrm{~V}$ (Fig. 1). In comparison, the background voltammetry is featureless over this range, indicating that the relatively large reduction current corresponds to the reduction of the $\left[\mathrm{WS}_{2} \mathrm{Cl}_{4}\right]^{2-}$ ions. On the return scan, the reduction current is lower, with a shoulder at $-1.15 \mathrm{~V}$ and then oxidation starts at $+0.5 \mathrm{~V}$, presumably due to oxidation of the deposited film.

To investigate the reduction of $\left[\mathrm{WS}_{2} \mathrm{Cl}_{4}\right]^{2-}$ we used the electrochemical quartz crystal microbalance (EQCM) technique. The voltammetry on the Pt EQCM electrode (Fig. 2a) shows essentially similar features, although these are now somewhat distorted by IR drop at the much larger electrode and show

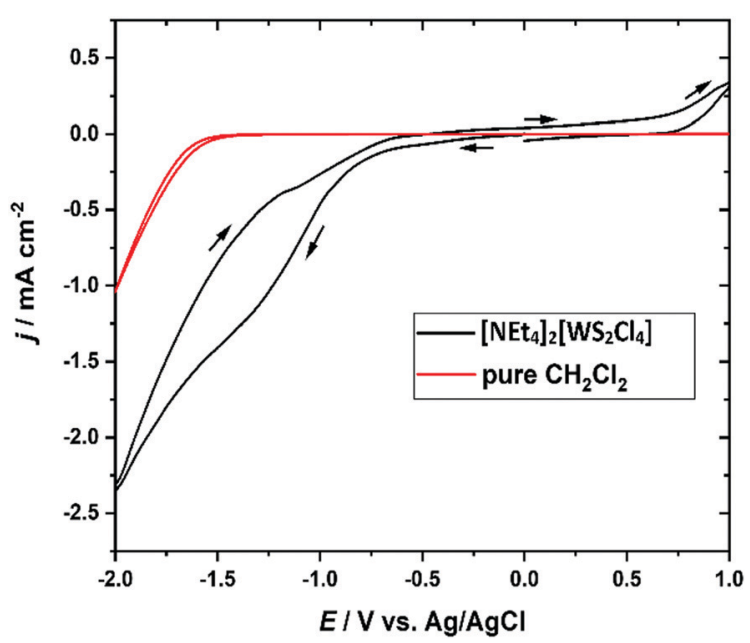

Fig. 1 Cyclic voltammogram of $5 \mathrm{mM}\left[\mathrm{NEt}_{4}\right]_{2}\left[\mathrm{WS}_{2} \mathrm{Cl}_{4}\right]$ in $\mathrm{CH}_{2} \mathrm{Cl}_{2}$ on a TiN electrode. The red line shows the background $\mathrm{CV}$ for $\mathrm{CH}_{2} \mathrm{Cl}_{2}$. The supporting electrolyte is $0.1 \mathrm{M}\left[\mathrm{N}^{n} \mathrm{Bu}_{4}\right] \mathrm{Cl}$ and the scan rate is $50 \mathrm{mV} \mathrm{s}^{-1}$. Arrows indicate the direction of potential scanning and the starting potential is $0 \mathrm{~V}$.
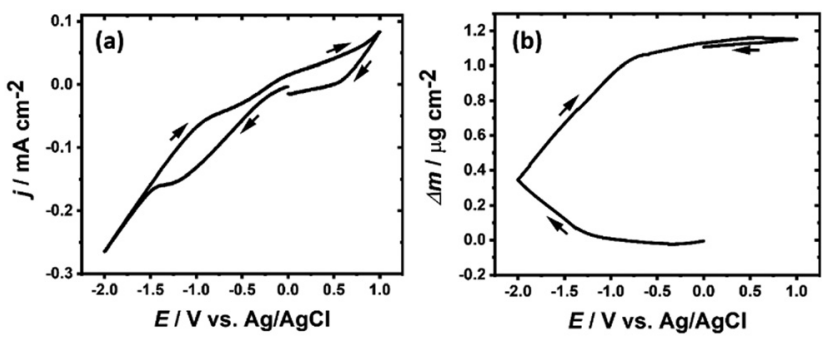

Fig. 2 (a) $\mathrm{CV}$ of $5 \mathrm{mM}\left[\mathrm{NEt}_{4}\right]_{2}\left[\mathrm{WS}_{2} \mathrm{Cl}_{4}\right]$ in $\mathrm{CH}_{2} \mathrm{Cl}_{2}$ on Pt coated quartz electrode. (b) The corresponding mass changes during the $\mathrm{CV}$. The supporting electrolyte is $0.1 \mathrm{M}\left[\mathrm{N}^{n} \mathrm{Bu}_{4}\right] \mathrm{Cl}$ and the scan rate is $50 \mathrm{mV} \mathrm{s}^{-1}$.

more significant oxidation at positive potentials, which is attributed to reaction of $\mathrm{Cl}^{-}$on the $\mathrm{Pt}$ electrode. Following the mass changes on the EQCM shows that the reduction of the $\left[\mathrm{WS}_{2} \mathrm{Cl}_{4}\right]^{2-}$ is associated with an increase in mass starting from $-1.2 \mathrm{~V}$, which continues as the reduction potential increases to $-2.0 \mathrm{~V}$ and then on the return scan to $-0.7 \mathrm{~V}$ (Fig. 2b). This mass increase is coincident with the reduction wave observed in the $\mathrm{CV}$ and consistent with deposition of $\mathrm{WS}_{2}$. The possible electrochemical reduction reaction at the cathode is,

$$
\left[\mathrm{WS}_{2} \mathrm{Cl}_{4}\right]^{2-}+2 \mathrm{e}^{-} \rightarrow \mathrm{WS}_{2}+4 \mathrm{Cl}^{-}
$$

This is further confirmed by performing a potentiostatic deposition on the EQCM by polarising the working electrode at $-1.3 \mathrm{~V}$ and recording the frequency change, which showed an approximately linear increase of mass with time (Fig. S6 ESI $\dagger$ ). The reduction potentials of $\left[\mathrm{WS}_{2} \mathrm{Cl}_{4}\right]^{2-}$ are well removed from the cathodic breakdown of the solvent and therefore has higher faradaic efficiency $(\sim 25 \%)$ compared to $\mathrm{MoS}_{2}$ electrodeposition in $\mathrm{CH}_{2} \mathrm{Cl}_{2}$. Note that the current efficiency for $\mathrm{MoS}_{2}$ electrodeposition was $<10 \%$ because the majority of the charge passed was used for the cathodic decomposition of $\mathrm{Me}_{3} \mathrm{NHCl}$ and the consequent $\mathrm{H}_{2}$ evolution at the cathode. ${ }^{9}$

To confirm the deposition of $\mathrm{WS}_{2}$, potentiostatic electrodeposition was carried out onto a TiN substrate for $1 \mathrm{~h}$ at $-1.3 \mathrm{~V}$. The as-deposited thin film was shown to be amorphous via $\mathrm{X}$-ray diffraction and was annealed in a tube furnace at $100{ }^{\circ} \mathrm{C}$ for $10 \mathrm{~min}$ followed by $500{ }^{\circ} \mathrm{C}$ for $2 \mathrm{~h}$ under $\mathrm{N}_{2}$ in a sulfur atmosphere. X-Ray diffraction of the annealed sample confirms the presence of crystalline $\mathrm{WS}_{2}$ (Fig. 3). Scanning electron microscope (SEM) images of the annealed $\mathrm{WS}_{2}$ deposit show a continuous and reasonably flat film with some cracks (Fig. 4a). The applied potential is found to have an effect on the roughness of the films as a thin film obtained at higher negative potential of $-1.7 \mathrm{~V}$ shows a smoother deposit with a thickness of around $30 \mathrm{~nm}$ and roughness of $2.5 \mathrm{~nm}$ measured by AFM (Fig. S8, ESI $\dagger$ ). Energy dispersive X-ray (EDX) analysis of the deposit shows signals at $1.75 \mathrm{keV}$, indicating the presence of $\mathrm{W}$ and/or $\mathrm{Si}$ and at $2.3 \mathrm{keV}$ showing the presence of $\mathrm{S}$ (Fig. 4b). Signals for Si, Ti and $\mathrm{N}$ from the electrode substrate are also visible. The small oxygen signal detected in the films could be due either to the surface oxidation of the film by atmospheric oxygen or to the diffusion of $\mathrm{O}_{2}$ into the film upon 


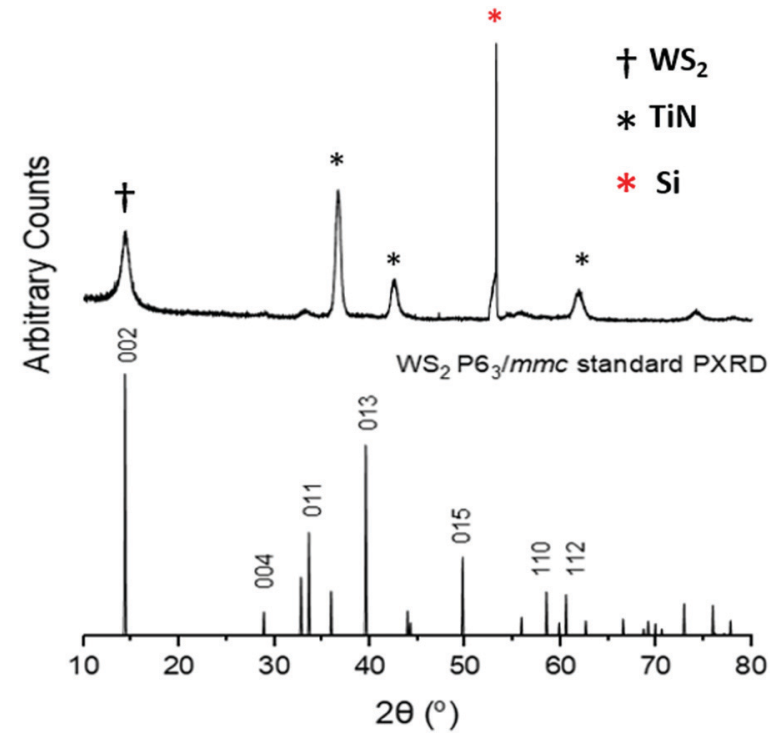

Fig. 3 Grazing incidence XRD pattern (top) from $\mathrm{WS}_{2}$ electrodeposited from $\left[\mathrm{NEt}_{4}\right]_{2}\left[\mathrm{WS}_{2} \mathrm{Cl}_{4}\right]$ in $\mathrm{CH}_{2} \mathrm{Cl}_{2}$. XRD pattern for bulk $\mathrm{WS}_{2}$ (bottom). ${ }^{1}$
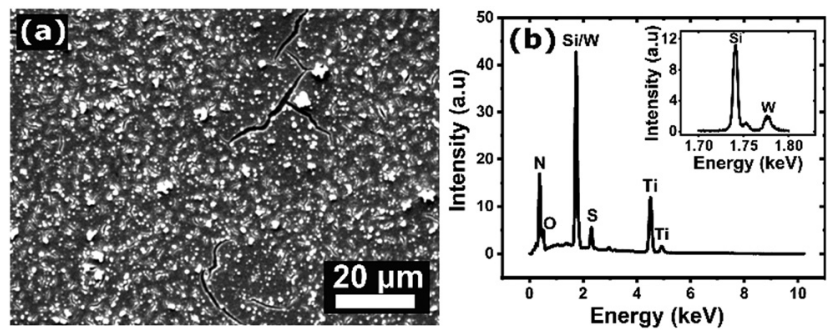

Fig. 4 (a) Top-view SEM image of the annealed deposit obtained after potentiostatic deposition at $-1.3 \mathrm{~V}$ for 60 minutes from $\mathrm{CH}_{2} \mathrm{Cl}_{2}$ containing $5 \mathrm{mM}\left[\mathrm{NEt}_{4}\right]_{2}\left[\mathrm{WS}_{2} \mathrm{Cl}_{4}\right]$ with $0.1 \mathrm{M}\left[\mathrm{N}^{n} \mathrm{Bu}_{4}\right] \mathrm{Cl}$ supporting electrolyte. (b) EDX profile of the deposited film after annealing. The inset shows WDX spectrum for Si and W.

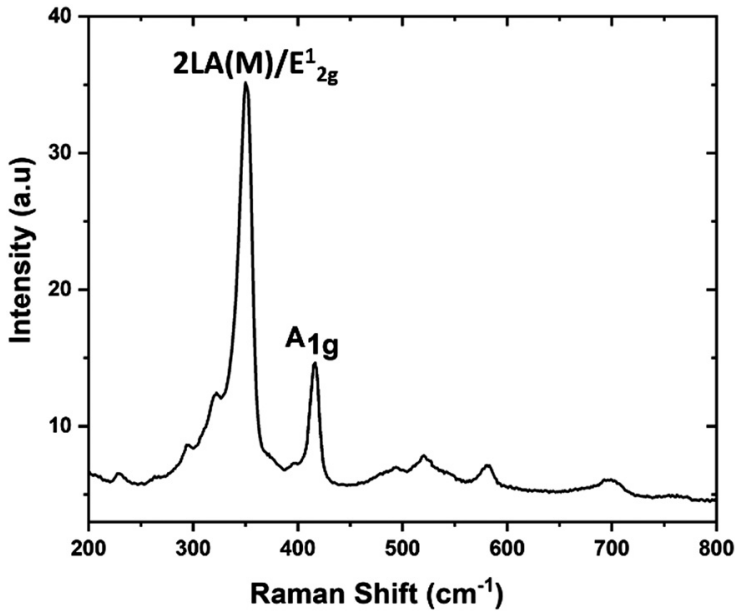

Fig. 5 Raman spectrum recorded from annealed $W_{2}$ deposit using $532 \mathrm{~nm}$ laser excitation. handling in ambient atmosphere. In the EDX spectrum, the $\mathrm{Si}-\mathrm{K}_{\alpha}(1.74 \mathrm{keV})$ and $\mathrm{W}-\mathrm{M}_{\alpha}(1.77 \mathrm{keV})$ peaks appear overlapped due to the low spectral resolution of the technique and so in order to confirm the presence of $\mathrm{W}$ and to determine the elemental composition, we used wavelength dispersive X-ray (WDX) spectroscopy to resolve these two peaks (Fig. 4b inset). Together, the EDX and WDX spectra confirm that the deposit contains both $\mathrm{W}$ and $\mathrm{S}$ with no significant impurities. The elemental composition obtained from the EDX/WDX spectra of both the as-deposited and annealed films show the $\mathrm{W}: \mathrm{S}$ ratio is $1: 2$. This is further confirmed by XPS measurements (Fig. S9, ESI†).

The Raman spectrum of the annealed deposit at $532 \mathrm{~nm}$ laser excitation shows the two main peaks at 352 and $419 \mathrm{~cm}^{-1}$, assigned to the $2 \mathrm{LA}(\mathrm{M}) / \mathrm{E}^{1}{ }_{2 \mathrm{~g}}$ and $\mathrm{A}_{1 \mathrm{~g}}$ vibrational modes of $\mathrm{WS}_{2}$, respectively (Fig. 5). The weaker features present in the Raman spectra are also consistent with literature data for $\mathrm{WS}_{2} \cdot{ }^{21}$

In conclusion, electrodeposition of $\mathrm{WS}_{2}$ using the customised $\left[\mathrm{WS}_{2} \mathrm{Cl}_{4}\right]^{2-}$ precursor is achieved via a relatively simple process that occurs without the need to add a proton source to the solution to remove excess $\mathrm{S}$. The electrochemical reduction mechanism of $\left[\mathrm{WS}_{2} \mathrm{Cl}_{4}\right]^{2-}$ studied by the EQCM technique showed that the faradaic efficiency of the process is higher compared to $\mathrm{MoS}_{2}$ electrodeposition in $\mathrm{CH}_{2} \mathrm{Cl}_{2}$ with an added proton source. The as-deposited $\mathrm{WS}_{2}$ films are amorphous but can be crystallised by annealing at $500{ }^{\circ} \mathrm{C}$ under $\mathrm{N}_{2}$. The compositional and structural quality of the films were confirmed by XRD, SEM and Raman analysis, showing that electrodeposition from $\left[\mathrm{WS}_{2} \mathrm{Cl}_{4}\right]^{2-}$ allows deposition of films with good homogeneity and good reproducibility in composition. This provides a simple, scalable and low-cost method for $\mathrm{WS}_{2}$ thin film deposition. This room temperature process also paves the way for future work on TMDC growth onto flexible substrates.

We thank the EPSRC for funding via EP/P025137/1, EP/ N509747/1, and the ADEPT programme grant (EP/N035437/1).

\section{Conflicts of interest}

There are no conflicts to declare.

\section{References}

1 W. J. Schutte, J. L. De Boer and F. Jellinek, J. Solid State Chem., 1987, 70, 207-209.

2 S. Manzeli, D. Ovchinnikov, D. Pasquier, O. V. Yazyev and A. Kis, Nat. Rev. Mater., 2017, 2, 17033.

3 Q. Ji, Y. Zhang, Y. Zhang and Z. Liu, Chem. Soc. Rev., 2015, 44, 2587-2602.

4 D. E. Smith, V. K. Greenacre, A. L. Hector, R. Huang, W. Levason, G. Reid, F. Robinson and S. Thomas, Dalton Trans., 2020, 49, 2496-2504.

5 M. Mattinen, T. Hatanpää, T. Sarnet, K. Mizohata, K. Meinander, P. J. King, L. Khriachtchev, J. Räisänen, M. Ritala and M. Leskelä, Adv. Mater. Interfaces, 2017, 4, 1700123.

6 J. D. Yao, Z. Q. Zheng and G. W. Yang, Prog. Mater. Sci., 2019, 106, 100573.

7 A. S. Aliyev, M. Elrouby and S. F. Cafarova, Mater. Sci. Semicond. Process., 2015, 32, 31-39.

8 H.-C. Shin, J. Dong and M. Liu, Adv. Mater., 2003, 15, 1610-1614.

9 S. Thomas, D. E. Smith, V. K. Greenacre, Y. J. Noori, A. L. Hector, C. H. D. Groot, G. Reid and P. N. Bartlett, J. Electrochem. Soc., 2020, 167, 106511. 
10 E. A. Ponomarev, A. Albu-Yaron, R. Tenne and C. Lévy-Clément, J. Electrochem. Soc., 1997, 144, L277-L279.

11 D. W. Redman, M. J. Rose and K. J. Stevenson, Langmuir, 2017, 33, 9354-9360.

12 Y. J. Noori, S. Thomas, S. Ramadan, D. E. Smith, V. K. Greenacre, N. Abdelazim, Y. Han, R. Beanland, A. L. Hector, N. Klein, G. Reid, P. N. Bartlett and C. H. de Groot, ACS Appl. Mater. Interfaces, 2020, 12, 49786-49794.

13 L. Fan and I. I. Suni, J. Electrochem. Soc., 2019, 166, A1471-A1480.

14 Z. Pu, Q. Liu, A. M. Asiri, A. Y. Obaid and X. Sun, Electrochim. Acta, 2014, 134, 8-12.

15 L. Fan and I. I. Suni, J. Electrochem. Soc., 2017, 164, D681-D686.
16 S. Jana, P. Bera, B. Chakraborty, B. C. Mitra and A. Mondal, Appl. Surf. Sci., 2014, 317, 154-159.

17 J. J. Devadasan, C. Sanjeeviraja and M. Jayachandran, J. Cryst. Growth, 2001, 226, 67-72.

18 P. Klingelhöfer and U. Müller, Z. Anorg. Allg. Chem., 1988, 556, 70-78.

19 V. K. Greenacre, A. L. Hector, W. Levason, G. Reid, D. E. Smith and L. Sutcliffe, Polyhedron, 2019, 162, 14-19.

20 K. M. Kadish and J. E. Anderson, Pure Appl. Chem., 1987, 59, 703-714.

21 M. Thripuranthaka, R. V. Kashid, C. S. Rout and D. J. Late, Appl. Phys. Lett., 2014, 104, 081911. 